\title{
Making DAM work for you - An insight into successful technology deployments
}

\begin{abstract}
Mukul Krishna
is responsible for the digital media practice at Frost \& Sullivan. He has written extensively on the enterprise content management, digital asset management, video server, video streaming and encoding services, and interactive kiosk markets. Mr Krishna has also led consulting projects in these fields for key clients. He has spoken at various speaking engagements on his area of expertise and is widely quoted in the press including major publications such as Forbes and the Washington Post. Mr Krishna is also on the Editorial Board of the Journal of Digital Asset Management and has been recently been nominated to be a Fellow at the Royal Society for Arts, Manufactures and Commerce in London, UK.
\end{abstract}

Keywords: digital asset management, return on investment, digital media, archive
management, North Plains Systems, TeleScope, rights management

Abstract Digital asset management (DAM) solutions have faced a lot of battles to see the market perception change from "nice to have" to "must have" for these solutions. This is now changing fast and the market is set to see some very healthy double-digit growth over the coming years. Just having a cool technology does not necessarily translate into a tool to solve a business challenge. A lot of work goes into making sure that the marriage between business processes and technology is a success. That comes when you have a solution rather than a product. DAM solutions have matured over the years and the related return on investment (ROI) is no longer seen as a leap of faith, as live deployments continuously show that the value proposition touted for so long is actually true, and backed by tangible numbers from corporations that were able to drive down their bottom line and gain business efficiencies through DAM implementations.

\section{INTRODUCTION}

Digital asset management (DAM) solutions have come a long way since the late 1990s when they started emerging as a market of their own. DAM solutions have slowly become regarded as "must have," though, due to lack of market awareness the solutions are still predominantly seen as "nice to have." This is now changing fast and the market is set to see some very healthy double-digit growth over the coming years.

One of the reasons why DAM solutions have taken some time to get to this point is timing. In its previous incarnation DAM was focused on the media and entertainment industry, which has been very conservative when it comes to spending, especially over the last five years. In addition, many early vendors tried riding the tech wave, promising customers the sky, leaving their customers with expensive solutions that failed to meet their requirements, forcing many of them to stay away from other vendors or look inwards to develop in-house solutions. All this was coupled with the tech market bust and the attacks of 11 September, 2001 effectively spelling doom for the DAM market; North Plains Systems, however, has maintained consistent and healthy growth during this time.

Surprisingly, most of the vendors survived the storm, took a step back, evaluated their products and strategies, and came back with more customer-focused solutions and strategies. Vendors are now more focused on using DAM as a brand management tool and are going for the corporate horizontal rather than any specific vertical market. North Plains has always had a horizontal approach and has since added vertical support through brand management, video management, and media distribution. Working with clients, the vendors have evolved their solutions into robust, scalable, and secure technologies; and greatly improved to better meet the challenges faced by their clients and help them achieve their return on investment (ROI). 
For this section of the Journal we will regularly feature key DAM companies and their products and how these companies have used their product offerings to solve specific customer challenges and provide tangible benefits to them. Some of the companies in the DAM market have been present since the very genesis of this space and have helped shape and evolve the landscape. One of these companies is North Plains Systems and the company's flagship product TeleScope. North Plains Systems is one of the key vendors in the market and based on Frost \& Sullivan's regular coverage of the market, the company has emerged as the market share leader for core digital asset management solutions for the last two years running.

\section{TELESCOPE: INNOVATION THAT PAYS FOR ITSELF}

Digital asset management accelerates business process cycle times without sacrificing quality and consistency. It reduces the time spent for product launches and helps companies get products to global markets ahead of the competition. And, it enables companies to capitalize digital assets through standard accounting practices.

North Plains Systems' TeleScope Enterprise can fully manage any digital content, enabling world-class organizations to turn their scattered collections of digital files into a secure repository of digital assets with real financial value. Those assets instantly become accessible for reuse, repurpose or reexpression, and choosing the right system to facilitate this will produce a solid return on investment.

North Plains' clients report a faster than average ROI from innovations such as asset activity tracking, custom plug-ins, uncompromised native Macintosh and Windows clients, a full-featured web client and a patentpending distributed architecture. With its open application programming interface (API) and support of industry standards, TeleScope is one of the only truly scalable enterprise-class asset management solutions for actual system deployment. North Plains Systems also offers a complete suite of professional services to implement and customize TeleScope to the business practices and workflow of any organization.

North Plains' core development and engineering team has been intact since 1994, when the TeleScope product family was introduced. Now, with ten years of research and development behind the technology, TeleScope serves more than 400 customers worldwide, making it arguably the largest installed base of asset management solutions and an ongoing source of third-party support and confidence for its customers. TeleScope Enterprise is used by some of the world's leading companies including AOL Time Warner, Boeing, Warner Bros., International Monetary Fund, Frankel \& Company (a Publicis company), Harcourt Education, Quebecor World, Sony Pictures, and HarperCollins Publishers.

With TeleScope, North Plains' clients are able to scale to billions of assets as the enterprise solution can be quickly rolled out to a number of business units in a large organization, thereby proving its value at implementation.

TeleScope gives production staff, vendors, licensees, partners, and consumers the ability to extract components of existing documents and dynamically generate new media assets repurposed for a wide variety of electronic and wireless delivery methods.

\section{KEY POINTS}

From its inception, North Plains Systems' products, applications, and services have been focused on the users. North Plains Systems was one of the first companies to recognize the requirements of the creative professionals and the necessity to support Windows and Macintosh clients through a feature-rich native client application for both. Even deeper than that is the support for the different classes of users of enterprise-class asset management: content creators, content editors, and content consumers.

Content creators are individuals who earn more than 50 per cent of their income producing content/digital media assets such as text, art, audio, and/or streaming media/video. Examples include animators, desktop publishers, content and web developers, audio effects and music producers, digital photographers and videographers, creative services staff, and multimedia publishers.

Content editors are individuals who earn less than 50 per cent of their income producing content/digital media, but use media to drive sales, markets, business and/or process 
improvements, and/or value enhancements for customers and shareholders. Examples include general creative staff, marketing and communications executives, training staff, and partners (channel, marketing, technology, etc).

Content consumers are individuals who earn nothing from their use or production of media, but use media to influence buying and selling, and/or sources of supply to fulfill self-service satisfactions. Examples include management, financial employees, sales, administration, human resources, research, customers, prospects, and the general public.

\section{DISTRIBUTED ARCHITECTURE}

TeleScope's unique distributed architecture provides secure global file management and access while allowing for considerable variation between both the infrastructure available at each location and processes employed by each functional team. A middleware layer is employed using intelligent "brokers" to effectively share system resources across the enterprise, maintain an accurate map of the location of all assets, and allow for differences in infrastructure, installed components, and platforms. Distributed media services may then be installed in any location to provide on-the-fly processing of graphics and text formatting in addition to offering location-specific system integration options.

\section{WORKFLOW ENGINE}

The workflow engine permits the TeleScope system administrator to define a set of "rules" or scripts, which can be executed when a user of the TeleScope client performs an action. Through customer feedback, North Plains discovered that restricting visibility to assets on a global level was not sufficiently granular to give customers the control they needed to meet every business challenge. Clients were clear that they wanted to define business rules where users of TeleScope could see some or all of the assets in the system, but that when they could see assets, their control or editing rights should be limited to a subset of assets. The workflow engine solves this business challenge. North Plains have designed the functional rules to empower clients to satisfy almost all possible business challenges in controlling users' permission levels, down to the asset, and actions that can be performed on those assets. In essence, the workflow engine is the holy grail that answers questions clients have regarding inter-departmental and/or business-tobusiness asset sharing.

\section{RIGHTS MANAGEMENT}

Rights management and the assurance that files are securely managed and distributed are challenges faced today by many enterprises. TeleScope allows organizations to individually control access or use of assets by applying dynamic rules for each asset or asset class. In addition to controlling access, TeleScope can also collect data on how the user intends to use the asset. Based on the user's response, access can be granted, denied or routed to the asset owner for approval.

\section{CONTENT INTEGRATION}

\section{Look-up broker}

The look-up broker provides a consistent interface to look-up services, and provides the following features:

- it allows the specification of multiple look-up "sources" for a given field, so that users can search across multiple different external systems for data to populate a given field

- it is architected as a modular, server-side component, so that new look-up methods can be added as needed

- it permits the look-up functionality to fill in metadata values not only for the field that has the look-up associated with it, but also for peripheral fields in the metadata model associated with the look-up field.

For a digital asset management system to be effective it must allow users to search and reference a robust set of metadata. The challenge for today's enterprises is that these metadata comes from various sources in various formats and at different levels of quality. Using the lookup broker option, organizations can consolidate all of these diverse data in TeleScope through a simple and easy-to-use interface.

The look-up broker option enables ondemand look-up of metadata from other data sources, such as retrieving an ISBN based on just the book title or finding a list of episodes from the name of a particular television program. 


\section{XML gateway}

An enterprise digital asset management system holds critical business data that need to be easily shared and distributed with other enterprise systems. TeleScope XML gateway provides a seamless platform to share data with other systems. TeleScope can interact with brand portal sites, knowledge management systems, content management systems, and even other digital asset management products.

\section{Return on investment}

Enterprise DAM represents a business strategy for accelerating business process cycle times. Depending on the nature of the cycle times required for different business models, enterprises will reap the interrelated benefits of improved time to market, process improvements, and cost reductions. Businesses whose revenues reflect short-term marketing investments (consumer packaged goods, entertainment, automotive, consumer electronics) achieve the best possible ROI due to the time-critical nature of their operations. However, even organizations whose businesses derive revenues from long-term contracts or long cycle infrastructure products, where time to market is less critical, still reap a positive ROI for DAM through process improvements and cost reductions.

TeleScope offers built-in tracking of asset and user activity with reporting available from within client applications and through the webbased interface. This interface provides information on who uses the assets, how they used them, and indicates how easily assets were located. However, DAM does not exist in a vacuum and the ability to easily implement enterprise-specific connections to external business data stores allows analytics to be developed, relating revenues and costs to assets and users. By merging the external data, enterprise wide analytics may be employed to relate assets to sales, determine degree of process improvement, and measure decreases in time to market.

Not only does TeleScope Enterprise increase productivity, it extends the client's investment in their digital assets, and opens up new revenue streams as it transforms files into valuable, multifunctional corporate assets. Asset management is a solution that needs to be deployed throughout an entire organization, and it will show a consistent ROI when implemented successfully. The adoption of DAM systems at the end-user level is crucial to the success of the system, and directly impacts ROI. Knowing this, North Plains Systems has developed TeleScope Enterprise with an award-winning interface that is user-friendly and intuitive. North Plains Systems also offers an ROI dashboard which can help clients understand the costs, and real value from choosing TeleScope.

\section{THOMSON LEARNING}

Thomson Learning is among the world's leading providers of lifelong learning information and services for both online and traditional classroom learning. Thomson Learning serves the needs of individuals, learning institutions, and

corporations.

Management of its digital assets and content is an integral part of the corporation's vision of providing interactive, customizable, integrated learning and teaching solutions: print, custom print, online courseware and remediation $(\mathrm{CD} /$ web), subscription-based services, online study tools and supplements, video, audio, and ebooks.

Until recently, Thomson Learning's archive management was a manual process handled by an outside vendor. Each time a book was submitted for archival or was requested for retrieval, Thomson Learning incurred fees. Turnaround times for requested content were anywhere from two to seven days. Thomson Learning quickly realized that they needed to deploy a modular asset management system to store their media independent assets and enable the repurposing, transformation, and output of those assets. The desired asset management system also needed to integrate with Thomson Learning's rights management and permission systems as well as existing custom publishing, ecommerce, financial, and business systems. Thomson Learning's business objectives related to implementation of a modular, enterprise digital asset management system were as follows: cut costs and eliminate turnaround time for the delivery of content from digital service and prepress providers; cut production costs incurred by having to recreate assets that existed in previous publications but could not be found or shared between operation companies; eliminate and consolidate all existing digital asset management 
stores across all of the operation companies; build an automated request and retrieval digital asset ordering system; and build an automated system to manage the archiving of digital assets.

Thomson started investigating DAM solutions sometime around the 1999-2000 timeframe. Previously, they had several small DAM systems at each operating company. Thomson went through a very thorough process prior to contacting North Plains. They initially contracted an outside independent systems integration firm to assist them in building a 71page document outlining the details of the requirements for integration between digital asset management and a content management system (CMS). At the time, with the assistance of the systems integrator, Thomson embarked on a pilot project to integrate a desktop solution, which is something they already had in-house, and another DAM vendor. In the end, that pilot project proved to Thomson that their current asset management products were not truly enterprise-class DAM systems and that tackling an integration between DAM and CMS was too much to tackle at one time. They then contacted North Plains and several other DAM vendors. After several meetings and custom demonstrations from North Plains and the other DAM vendors, Thomson selected North Plains' TeleScope.

The successful multi-business unit deployment of TeleScope is part of the global production and manufacturing group's overall content and asset management initiative.

TeleScope Enterprise is being used to support two distinct workflows as part of this global initiative - pre-production of new International Standard Book Numbers (ISBNs) and the archive management of existing ISBNs. TeleScope supports the pre-production workflow by enabling Thomson Learning to use a single, internal source to store, manage, and retrieve media independent assets; to repurpose, reuse and reexpress assets and to integrate with Thomson's own rights management and permissions systems. The deployment added further business units throughout 2004.

With the implementation of TeleScope, the control and ownership of Thomson Learning's assets have been returned to them. Additionally, an archive distribution portal based on
TeleScope.web, was created enabling Thomson Learning to manage the submission and distribution of archive assets, facilitate faster reuse and reexpression by reducing fulfillment times to less than a day, and inevitably to realize a higher ROI by eliminating fees associated with archive submission and retrieval.

TeleScope Enterprise's Order Processing module was implemented to handle the ordering of entire ISBNs, including the processing, approvals, tracking, and fulfillment of all orders. An extensive key wording strategy which includes over 250,000 terms with varying levels, utilizes TeleScope's look-up broker functionality, enabling users to search on approved terms and use them as part of the metadata for the asset. TeleScope Enterprise has streamlined workflows, making insertion, classification, rights information, and datamining simple and accurate. The archive distribution portal will be used by all business units within Thomson Learning.

Thomson Learning's asset management system (AMS) initiative is under the project leadership of Thomson Learning's global production and manufacturing group, which is a central services group that represents the North American and international Thomson Learning operating companies.

Thomson will utilize integrations with TeleScope's rights management system, key wording system, look-up broker, functional rules capabilities, modified web interface, indexing, archiving, and more. TeleScope is hosted on Sun Solaris/Oracle systems (enterprise systems).

Technical reasons for Thomson's selection of North Plains include TeleScope's native client for both Macintosh and Windows, fully functional web client interface, support of Thomson's existing infrastructure with Sun Solaris and Oracle enterprise systems, and the easy integration with Thomson's other business systems. North Plains' TeleScope also has the ability to easily integrate with future content management systems via TeleScope's web services interface.

In short, books at Thomson are now produced smarter, cheaper, and more rapidly ultimately adding to Thomson's bottom line. Some of the final technology enhancements may not have been envisioned by Thomson upon 
their initial conception of the project, but were added or were a result of the innovation that they were able to achieve through close interaction with their vendor, North Plains.

\section{THE BOTTOM LINE}

Simply having a cool technology does not necessarily translate into a tool to solve a business challenge. A lot of work goes into making sure that the marriage between business processes and technology is a success. This is when you have a solution rather than a product.

North Plains Systems' adaptable solution allows Thomson to meet demanding customer requirements and TeleScope's feature depth means no customizations and a lower cost of ownership.

Thomson not only needed a technology that would address the challenges they identified, but a technology provider with proven success with other large-scale deployments. North Plains Systems' professional services group also proactively worked with Thomson to figure out how TeleScope could best meet those challenges and at the same time helped Thomson identify other challenges. This professional services methodology delivered the Thomson DAM project on time and under budget. 